\title{
SELF ADAPTIVE RULE-BASED SPEED CONTROLLER FOR A SYMMETRICAL ANGLE CONTROLLED DC MOTOR
}

\author{
E.E. El-Kholy, and S. S. Shokralla \\ Electrical Engineering Department, Faculty of Engineering, \\ Shebin El-Kom, Minoufiya University, Egypt. \\ e-mail: eelkholy@hotmail.com
}

\begin{abstract}
:
This paper presents modeling, numerical simulation and experimental behavior for dynamic and steady state performance of a separately excited DC motor. The motor is fed from AC to DC symmetrical angle controlled converter. An intelligent variable gain rule-based speed controller for speed reference tracking is proposed. The error-driven error-scaled adaptable gain speed controller allows flexible and robust control of this system. The control scheme has been implemented using Digital Signal Processor.
\end{abstract}

\section{LIST OF MAIN SYMBOLS:}

A : Maximum voltage signal.

B : Viscous friction coefficient.

$\mathrm{C}_{\mathrm{f}} \quad$ : Filter capacitance.

F : : Supply frequency

$i_{\mathfrak{m}} \quad:$ Instantaneous armature current.

$\mathrm{i}_{\mathrm{s}} \quad$ : Instantaneous supply current.

$\mathrm{J} \quad$ : Moment of inertia.

$\mathrm{K}_{0} \quad$ : Fixed gain.

$\mathrm{L}_{\mathrm{m}}, \mathrm{r}_{\mathrm{m}} \quad$ : Armature inductance and resistance.

$\mathrm{K}_{\mathrm{m}} \quad$ : Back e.m.f. Constant.

$\mathrm{L}_{\mathrm{f}}, \mathrm{R}_{\mathrm{f}} \quad$ : Filter inductance and resistance.

$\mathrm{T}_{\mathrm{L}} \quad$ : Load torque.

$\mathrm{T}_{\mathrm{s}} \quad$ : The sampling period. 


$\begin{array}{ll}\mathrm{V}_{\mathrm{s}} & : \text { Instantaneous supply voltage. } \\ \mathrm{V} & : \text { Peak value of supply voltage. } \\ \mathrm{V}_{\mathrm{c}} & : \text { Control voltage. } \\ \mathrm{V}_{\mathrm{m}} & : \text { Motor voltage. } \\ \omega & : \text { Supply angular velocity. } \\ \omega_{\mathrm{m}} & : \text { Motor angular velocity. } \\ \omega_{\text {ref }} & : \text { Reference angular velocity. } \\ \omega_{\text {base }} & : \text { Base angular velocity. } \\ \gamma_{1}, \gamma_{2}, \gamma_{3} & : \text { Fixed gains optimized off-line. }\end{array}$

\section{INTRODUCTION:}

Direct current motor drives are used extensively in industries such as steel mill; paper mill, conveyors, chemical, etc.... In many drive applications, the mechanical load varies considerably during operation. Robots and machine tools are two examples. When a fixed controller setting is used for a DC drive system with wide load changes, unsatisfactory performance is often produced [1-2].

High performance DC motor drives are important for multitude of industrial applications [3-5]. Precise, fast, effective speed reference tracking with minimum overshoot/undershoot and small steady-state error are essential control objectives. Conventional controllers are usually used for fixed structure, and fixed parameter design [6-8]. Tuning and optimization of these controllers are challenging and difficult task, particularly under varying load conditions, and abnormal operation.

An artificial intelligent system based on fuzzy logic and neural network techniques was reported for a high performance DC drive [9]. A simulation study for an intelligent rule-based error driven gain scheduling controller for a chopper fed DC series motor was proposed in reference [10]. Alternatively, an intelligent self-adaptive rule based speed regulator for a permanent magnet $D C$ motor drive is implemented in reference [11]. The dynamic and steady state performance of a symmetrical angle controlled DC motor is investigated, and the power factor of the system is improved using this technique. Also, the conventional analog proportional-integral controller is used for speed control[12].

In this paper, a new concept of intefligent error driven controller is proposed, where the control action is scaled on line and adjusted based on the excursion error magnitude and location in the error phase portrait. The results confirm the robustness of this controller to limit inrush current and also provide fast dynamic speed reference tracking for a DC motor drive. 


\section{SYSTEM DESCRIPTION:}

Figure (1) shows a schematic diagram for the proposed speed control system. It consists of a cascade combination of a diode bridge rectifier and a symmetrical angle control converter, connected to a single-phase AC supply. The motor voltage is regulated by the control voltage $\left(V_{c}\right)$ from zero to the maximum value (A) of the timing voltage $\left(\omega_{\mathrm{a}}\right)$ as shown in Fig. (2). The inductance $\mathrm{L}_{\mathrm{f}}$ and capacitance $C_{f}$ are used as an output DC filter. One MOSFT (Type IRFP450) is used, and controlled by an impulse generator. The gate pulses are generated as shown in Fig. (2), where the control voltage is the output from the Rule Based Error Driven Controller. The parameter values of this system are given in Appendix (1).

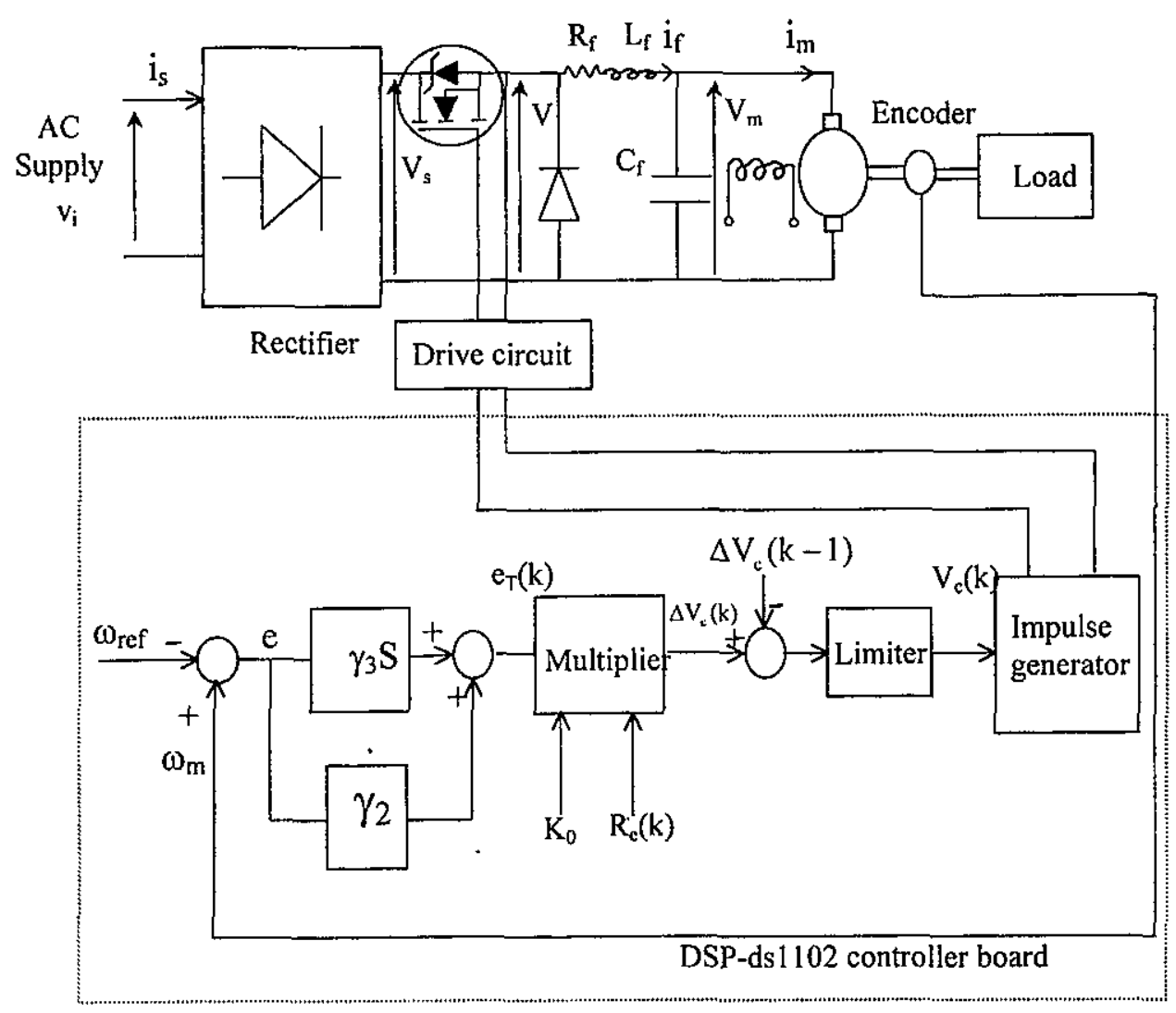

Fig. (1) System configuration

A fully digital control scheme has been implemented with a Digital Signal Processor (DSP-DS1102), and interfaced with a personal computer. The DSP (TMS320C31) controller board uses $40 / 32$ bit floating point/integer multiplier, arithmetic logic unit, $60 \mathrm{MHz}$ clock rate $33.3 \mathrm{n} . \mathrm{sec}$. cycle time, $8 \mathrm{Mbaud}$ serial interface and 4 external interrupts [13]. The circuits, such as logic, isolation, driving and measuring are implemented. The speed feedback signal $\left(\omega_{m}\right)$ is converted into a digital value by an incremental encoder interface. The control algorithm is implemented as software using high level $\mathrm{C}$ programming 
language. The output from DSP is used to drive the MOSFT switch through a driving circuit as shown in Fig. (1).

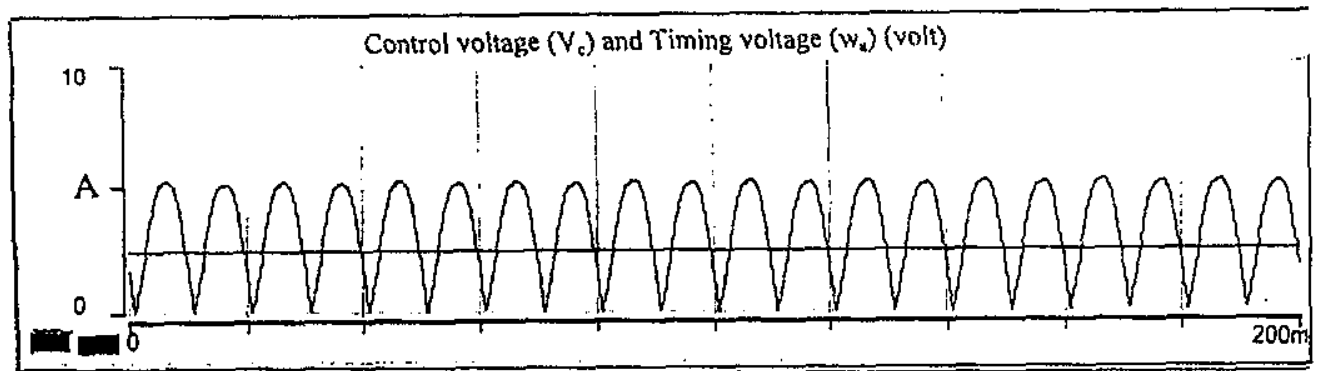

Gate pulses

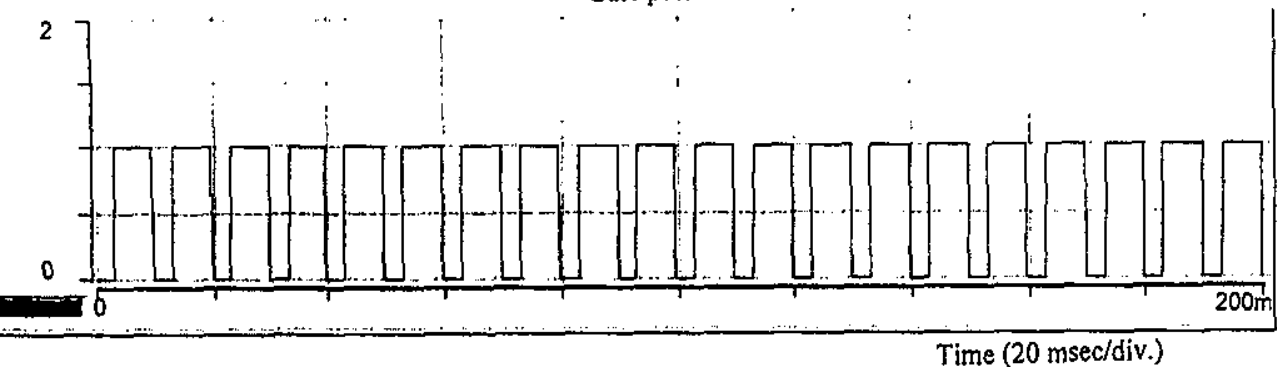

Fig. (2) Experimental result for the output of the pulse generator circuit

\section{SYSTEM MODELING:}

The system under investigation has two modes of operation. These modes are represented by the equivalent circuits of Fig. (3). The mathematical model can be obtained as follows:

\section{- Modeling Of The Power Circuit And Motor:}

Mode (1):

In this mode, the MOSFET is $O N$. The differential equations describing this mode are given as follows:

$$
\begin{aligned}
& L_{f}\left(\frac{d i_{f}}{d t}\right)=V_{s}-i_{f} R_{f}-V_{m} \\
& L_{m}\left(\frac{d i_{m}}{d t}\right)=V_{m}-i_{m} t_{m}-K_{m} \omega_{m}
\end{aligned}
$$




$$
\begin{aligned}
& J\left(\frac{d \omega_{m}}{d t}\right)=K_{m} i_{m}-B \omega_{m}-T_{L} \\
& C_{f}\left(\frac{d v_{m}}{d t}\right)=i_{f}-i_{m} \\
& i_{S}=i_{f} \\
& V_{S}=V|\sin (\omega t)|
\end{aligned}
$$

\section{Mode (2):}

In this mode, the MOSFT is OFF as shown in Figure (3). The differential equations describing this mode are given:

$$
\begin{aligned}
& L_{f}\left(\frac{d i_{f}}{d t}\right)=-V_{m}-i_{f} R_{f} \\
& L_{m}\left(\frac{d i_{m}}{d t}\right)=V_{m}-i_{m} r_{m}-K_{m} \omega_{m} \\
& J\left(\frac{d \omega_{m}}{d t}\right)=K_{m} i_{m}-B \omega_{m}-T_{L} \\
& C_{f}\left(\frac{d v_{m}}{d t}\right)=i_{f}-i_{m} \\
& i_{s}=0
\end{aligned}
$$

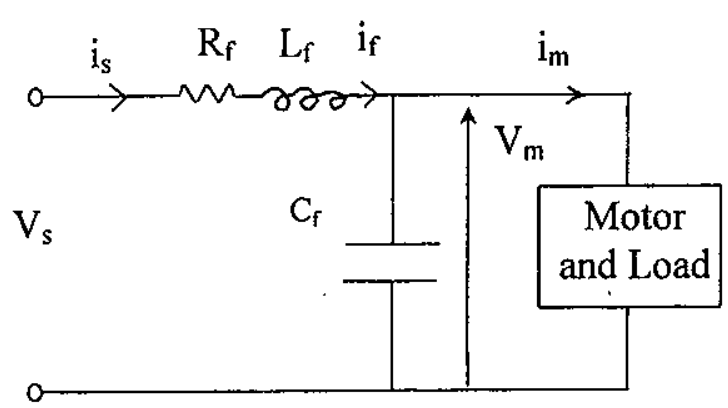

Mode (1) MOSFET is ON 


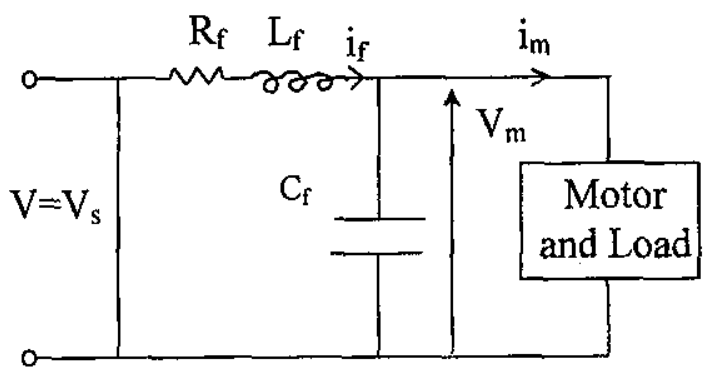

Mode (2) MOSFET is OFF

Fig. (3) Modes of operation for the system

\section{MODELING OF THE IMPULSE GENERATOR:}

From Fig. (2) the equation that represents the timing voltage $\left(\omega_{\mathrm{a}}\right)$ is given by:

$\omega_{a}=\mathrm{A}|\sin (\omega \mathrm{t})|$

The MOSFET is turned ON when:

$\mathrm{V}_{\mathrm{c}}<\omega_{\mathrm{a}}$

The MOSFET is turned OFF when:

$\mathrm{V}_{\mathrm{c}}>\omega_{\mathrm{a}}$

\section{EFFECT OF CONTROL VOLTAGE FOR OPEN-LOOP SYSTEM:}

Figure (4) shows the effect of varying the control voltage on the motor speed and supply input power factor for 0.5 and 0.75 full load torque [12]. It is observed that the motor speed is decreased with increasing of the control voltage $\left(\mathrm{V}_{c}\right)$. Also, it is noted that the input power factor varies in an acceptable range for such systems compared with thyristor fully controlled rectifier systems [14].

\section{MODELING OF THE RULE-BASED INTELLIGENT SPEED CONTROLLER:}

Figure (1) shows the basic control structure. The following equations describe the error $\left(\mathrm{e}_{\omega}\right)$ based control concept and the self-adaptability of the error driven, error scaled control scheme:

The speed error and its derivative is given by: 


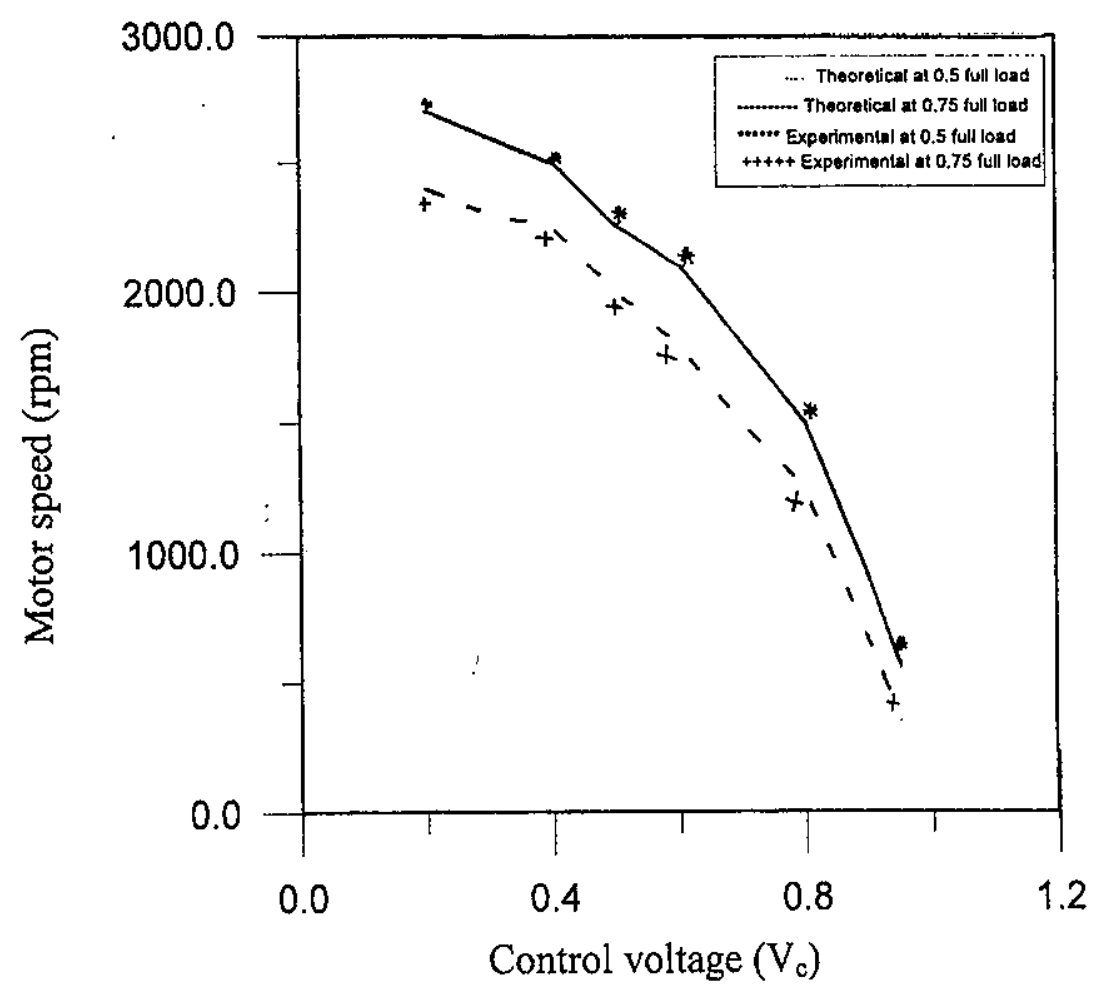

(a) Motor speed

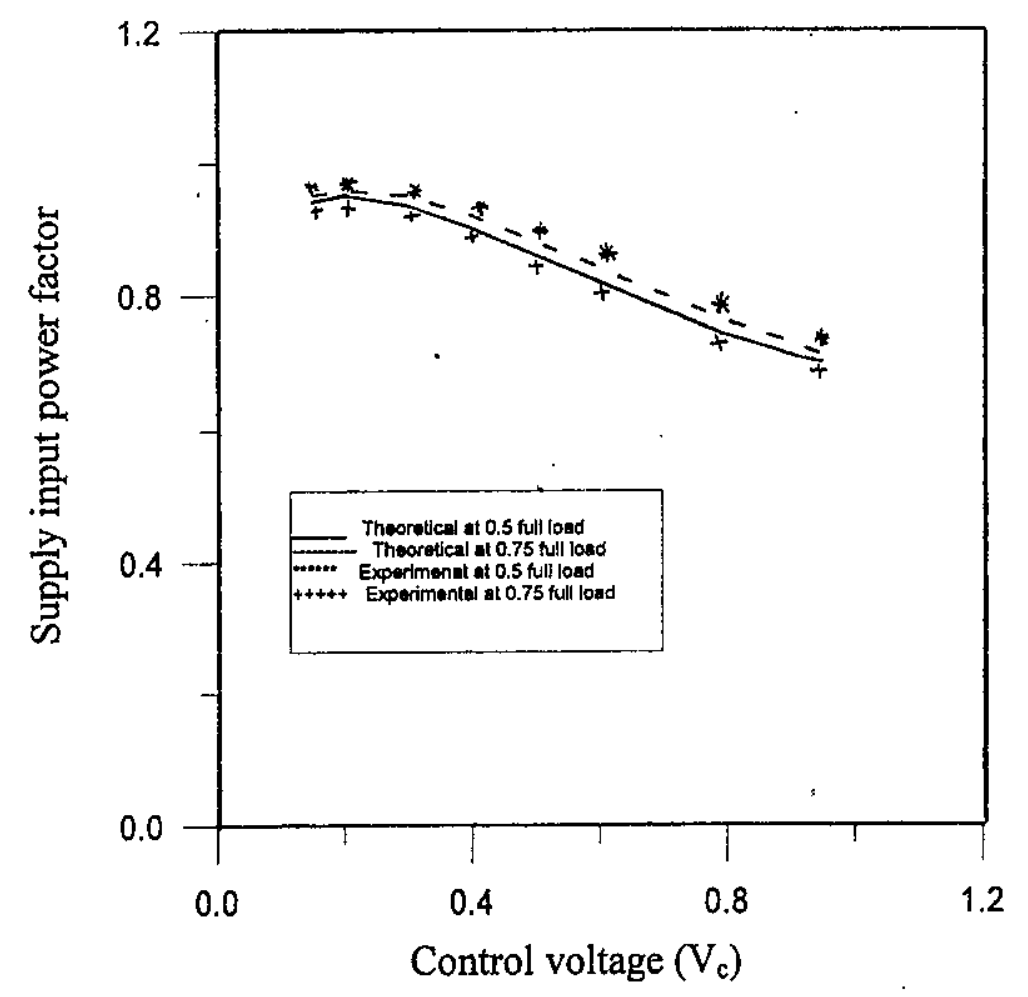

(b) Supply input power factor

Fig. (4) Effect of control voltage on the steady state characteristics 


$$
\begin{aligned}
& e_{\omega}(\mathrm{k})=\frac{\omega_{\text {ref }}(\mathrm{k})-\omega_{\mathrm{m}}(\mathrm{k})}{\omega_{\text {base }}} \\
& e_{\omega}^{\bullet}(\mathrm{k})=\frac{e_{\omega}(\mathrm{k})-e_{\omega}(\mathrm{k}-1)}{\mathrm{T}_{\mathrm{s}}}
\end{aligned}
$$

Where, $e_{\omega}(k)$ and $e_{\omega}{ }^{\circ}(k)$ defines the dynamic error phase portrait coordinates for the rule based intelligent speed excursion based variable gain controller [10-11].

The global error $\left(\mathrm{e}_{\mathrm{T}}\right)$ at any sampling time period $(\mathrm{k})$ is given by:

$$
e_{\mathrm{T}}(k)=\left[\gamma_{2} e_{\omega}(k)+\gamma_{3} e_{\omega}^{\bullet}(k)\right]
$$

The error scaling gain $\left[R_{e}(k)\right]$ is given by:

$$
R_{e}(k)=\left[\sqrt{e_{\omega}^{2}+\gamma_{1}^{2} e^{\bullet 2}}-R_{e o}\right] / \beta \beta
$$

Where, $R_{e o}$ is the dead zone to limit control instability and is equal to 0.03

The control modulation step is defined by:

$$
\Delta V_{c}(k)=K_{o} e_{T}(k) R_{e}(k)
$$

The final control action is an equivalent proportional plus integral action

$$
\mathrm{V}_{\mathrm{c}}(\mathrm{k})=\Delta \mathrm{V}_{\mathrm{c}}(\mathrm{k}-1)+\Delta \mathrm{V}_{\mathrm{c}}(\mathrm{k})
$$

Where $V_{c}(k)$ is the control voltage limited by the converter operation between (zero to $\mathrm{A}$ ) volts.

\section{SIMULATION AND EXPERIMENTAL RESULTS:}

The proposed system is designed and implemented to verify the developed model. The behavior of this system under steady state and transient conditions is determined by solving the nonlinear differential equations using the fourth order Runge-kutta method. The instantaneous values of the supply and the load are obtained from the proposed numerical simulation, as well as from experimental measurements. 


\section{- Steady-State Characteristic:}

Figure (5) shows samples of the steady state waveforms at $\omega_{\mathrm{ref}}=200 \mathrm{rad} / \mathrm{sec}$; for half load torque. It is observed that the motor current and voltage are considered as ripple free. Also, the motor speed is smooth. Moreover, the supply input power factor is improved. It is observed that the agreement between the measured and computed values is reasonable.
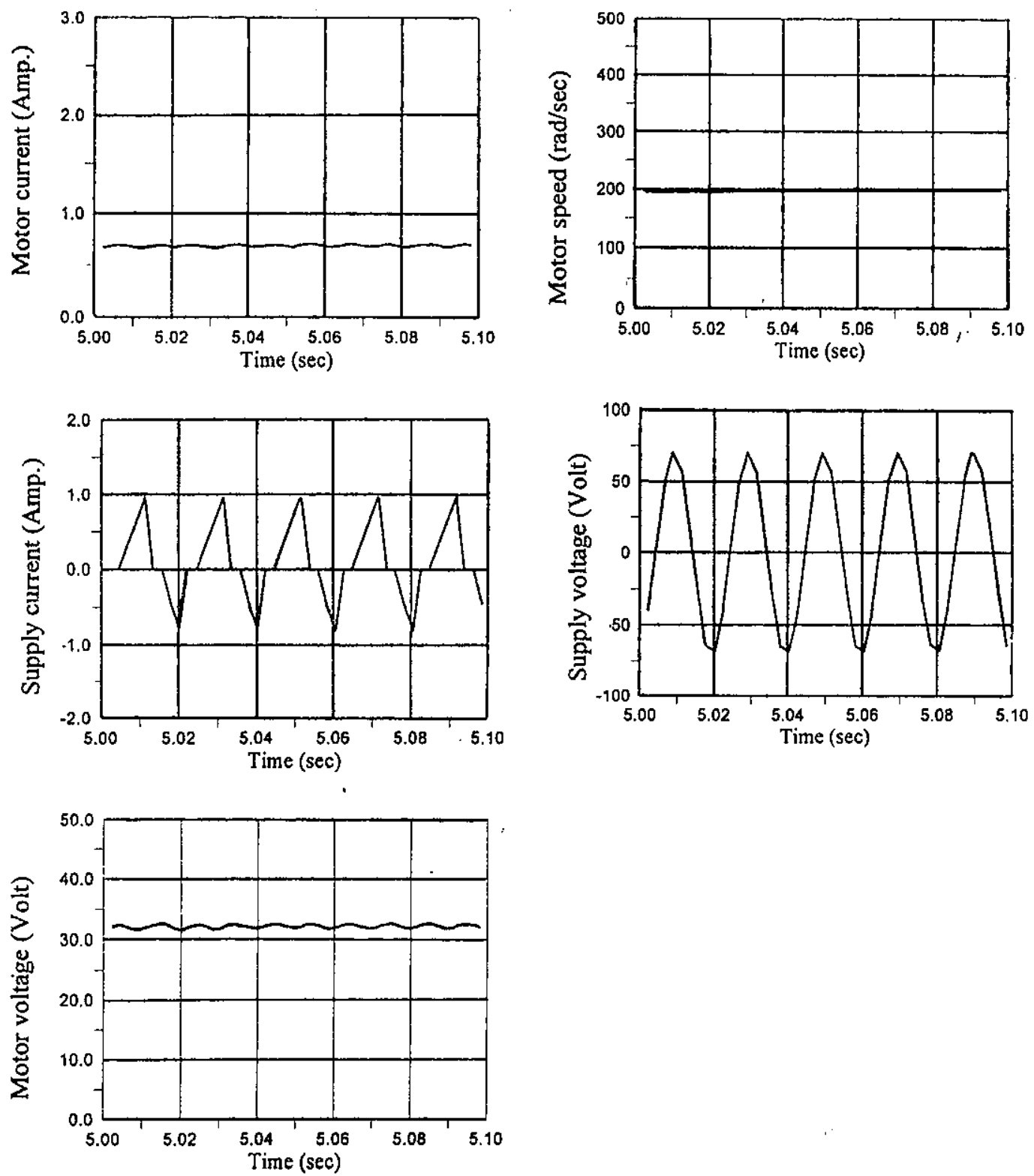

(i) Simulation 


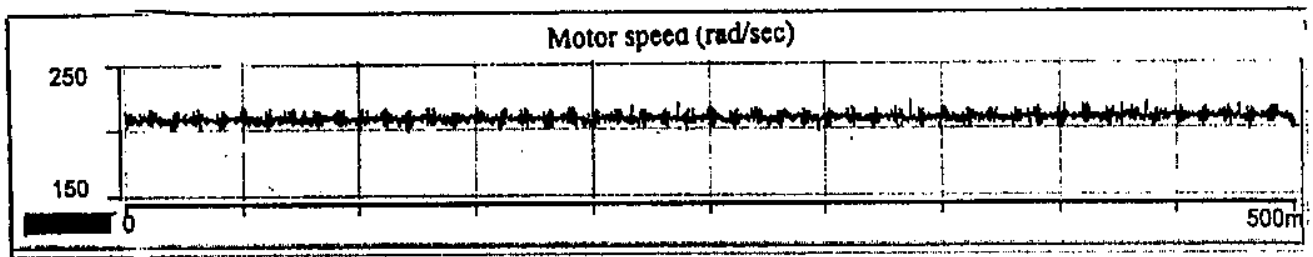

Supply current (Amp.)

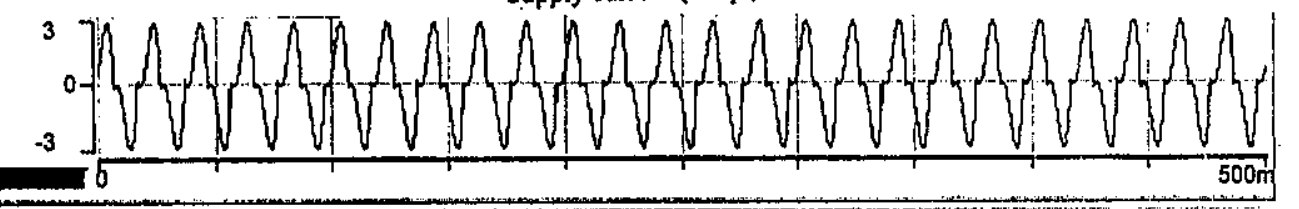

Supply voltage (volt)
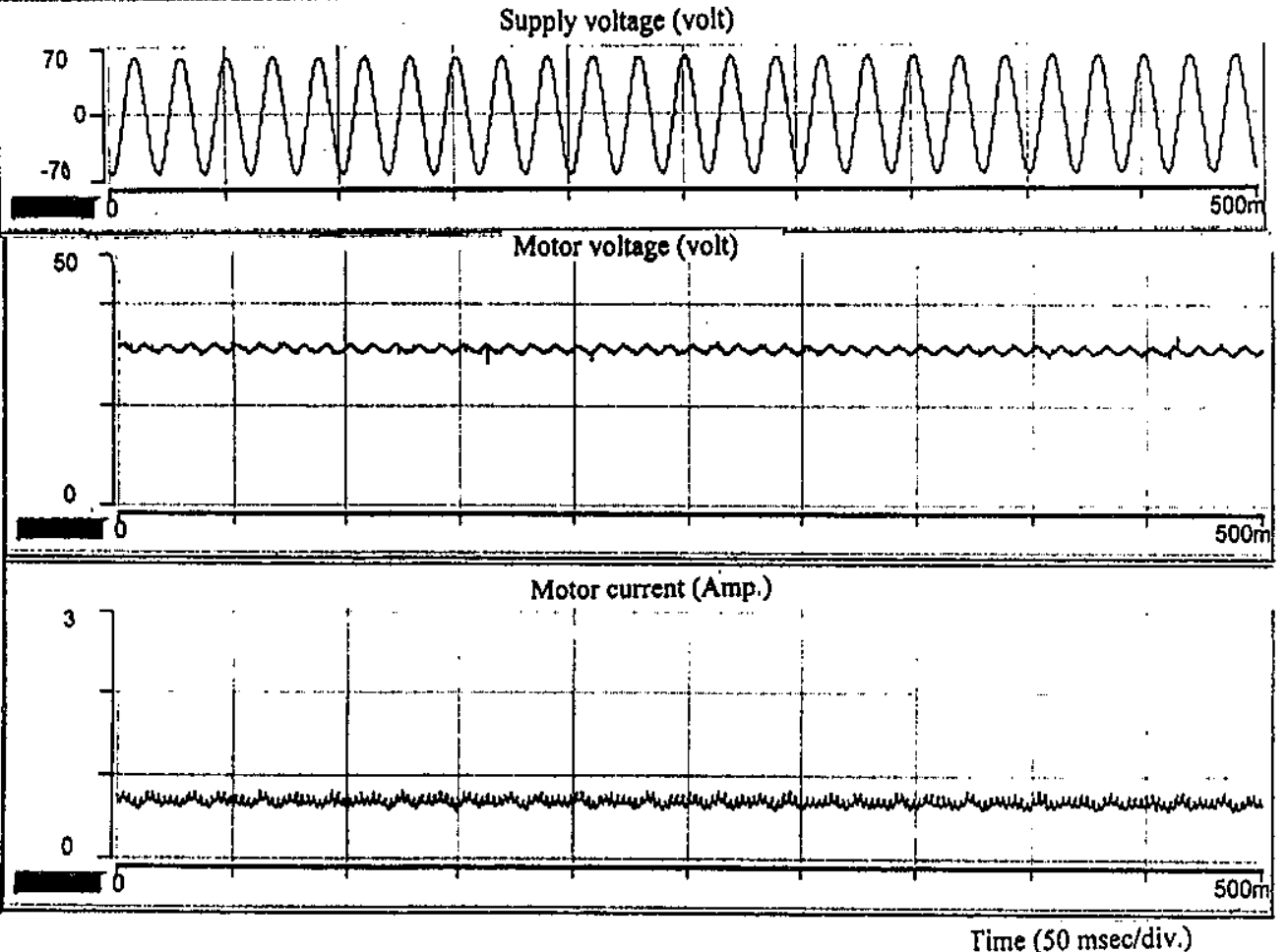

(ii) Experimental

Fig. (5) The steady state waveforms at half load

\section{- Starting Behavior:}

Figure (6) shows the waveforms of the motor voltage, current and speed during starting-up with half load and $\omega_{\text {ref }}=200 \mathrm{rad} / \mathrm{sec}$. It is noticed that the transient period is about $0.4 \mathrm{sec}$, which is considered a relatively long time for the motor under test. This is due to the motor electromechanical time constant which is large compared with the electrical time constant. 

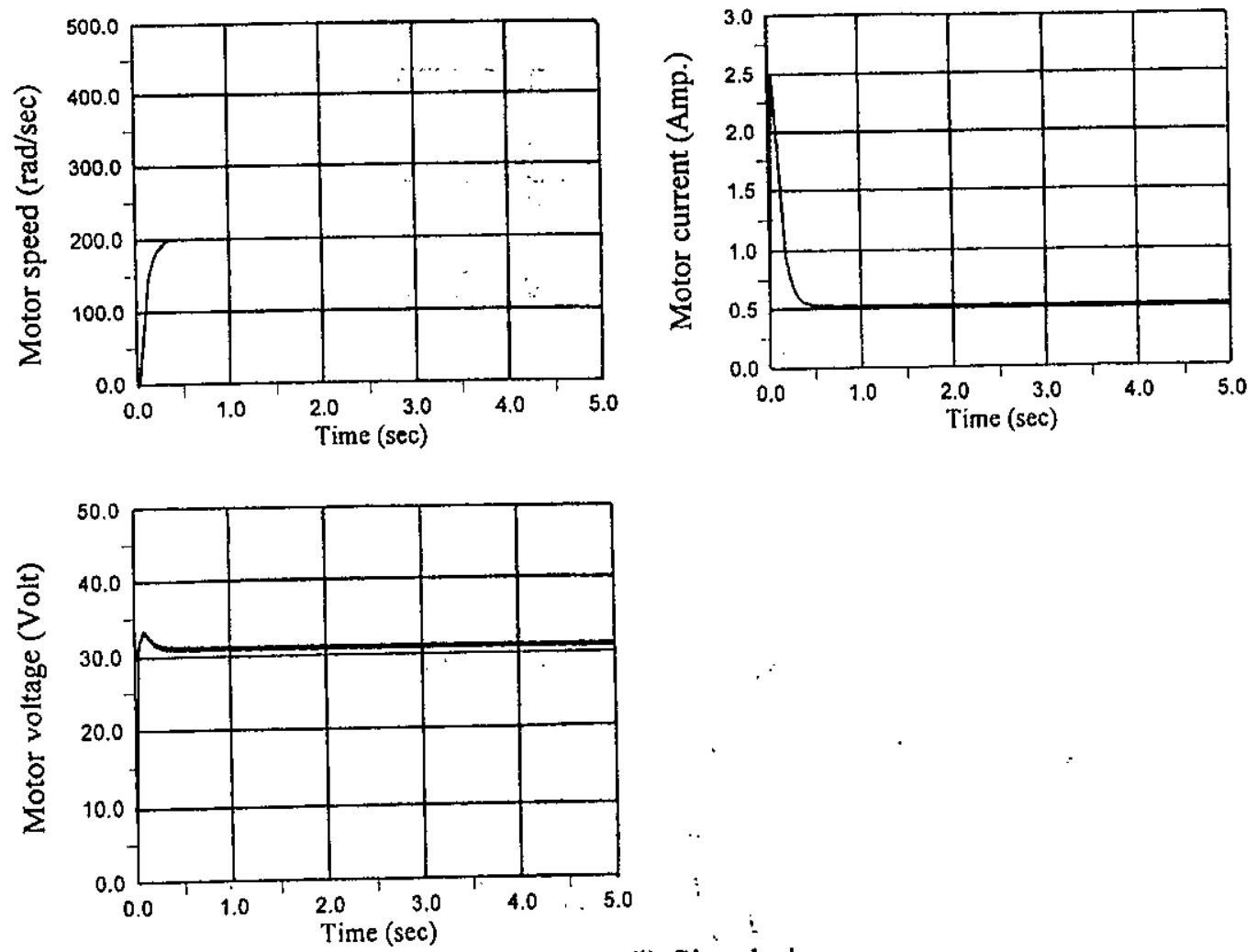

(i) Simulation

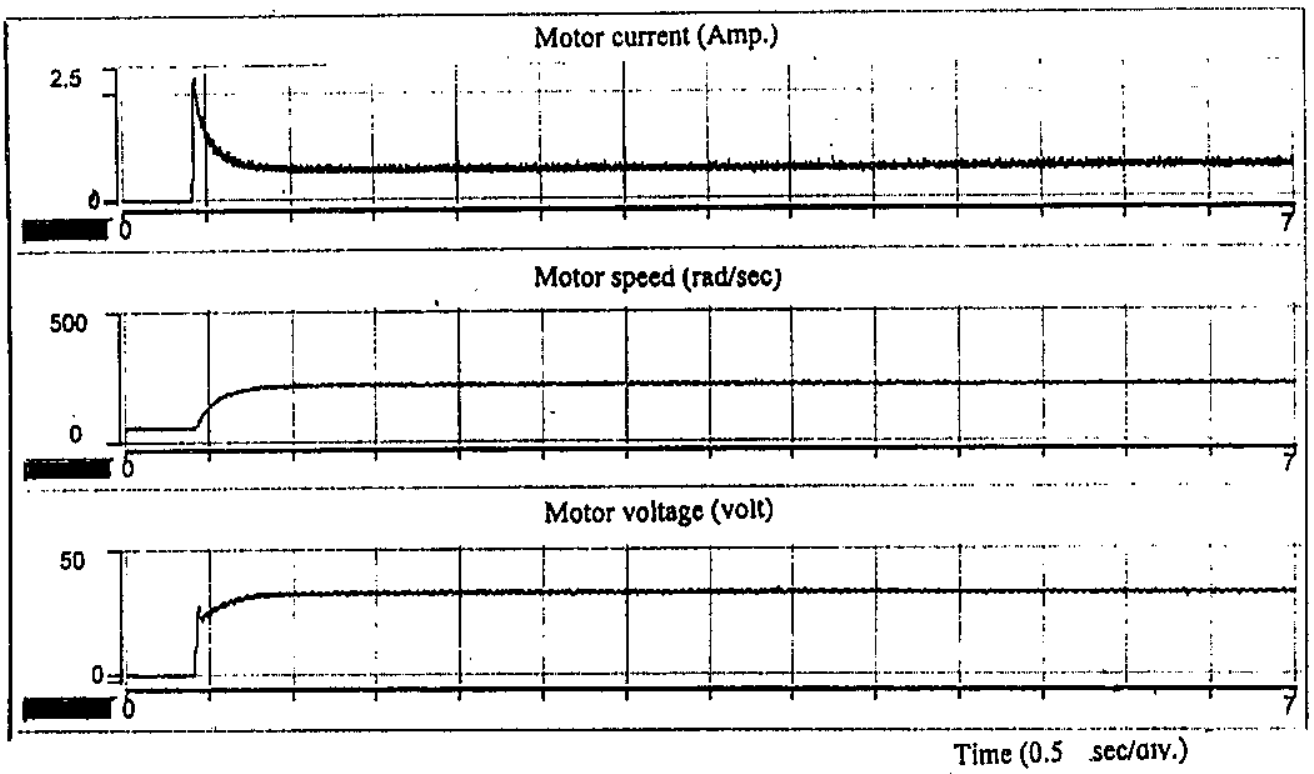

(ii) Experimental

Fig. (6) Run-up behavior for half load and $\omega_{\text {ref }}=200 \mathrm{rad} / \mathrm{sec}$

Figure (7) shows the ( $e_{\omega}-e_{\omega}^{0}$ ) phase portrait. 


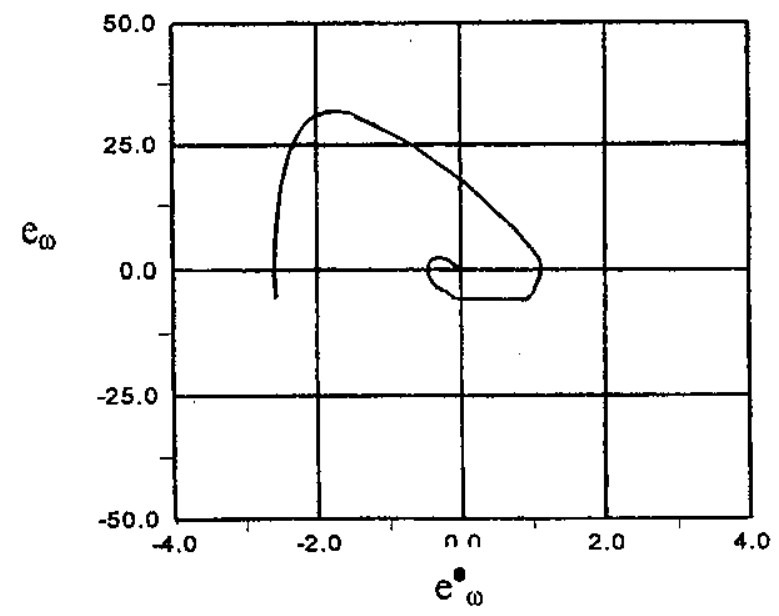

Fig. (7) The $\left(e_{\omega}-e^{0}\right)$ phase portrait [simulation results]

\section{- Load Torque Disturbance:}

Figure (8) shows the response of motor speed for an increase of the load torque from 0.5 to 0.75 of the rated value. It is observed that the motor speed has returned to its initial value after $400 \mathrm{msec}$.

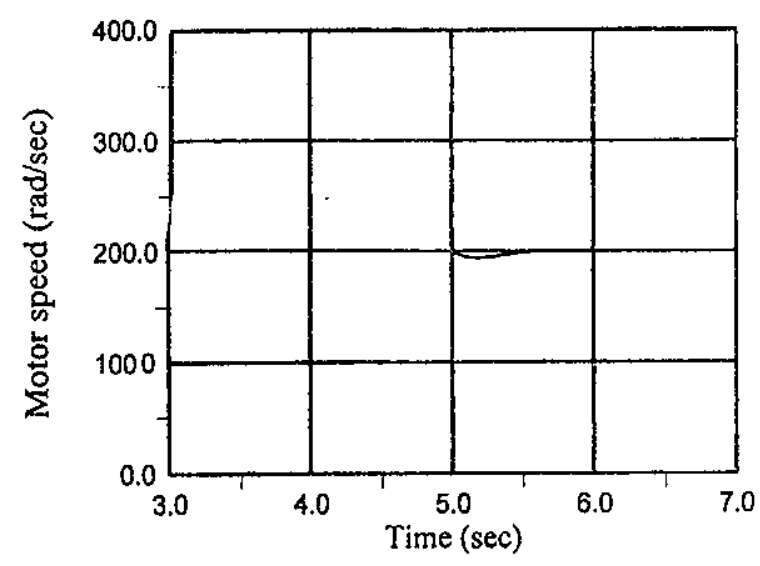

(i) Simulation

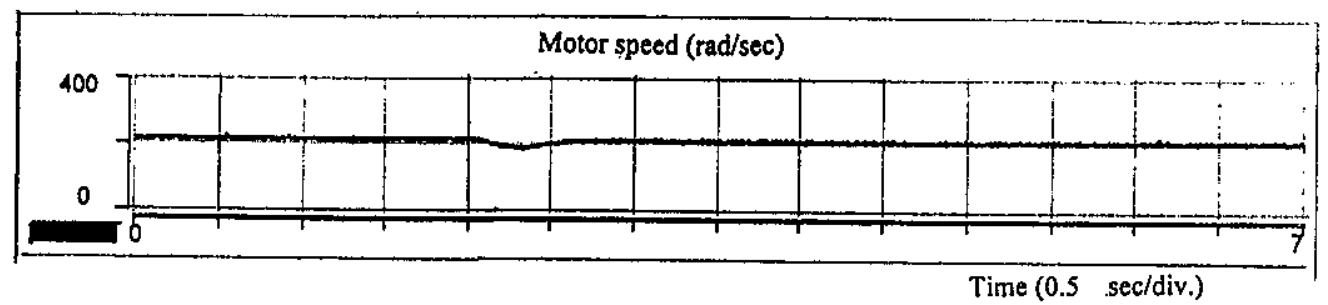

(ii)Experimental

Fig. (8) Response to a change in load torque from 0.5 to 0.75 of rated value with $\omega_{\mathrm{ref}}=200 \mathrm{rad} / \mathrm{sec}$. 
- Reference Voltage Step Change:

Figure (9) shows the motor voltage, current, and speed with a step change in speed reference $\left(\omega_{\text {ref }}\right)$ from 200 to 250 followed by a decrease from 250 to 200 $\mathrm{rad} / \mathrm{sec}$ at half load. It is observed that the motor can follow the desired speed reference smoothly.
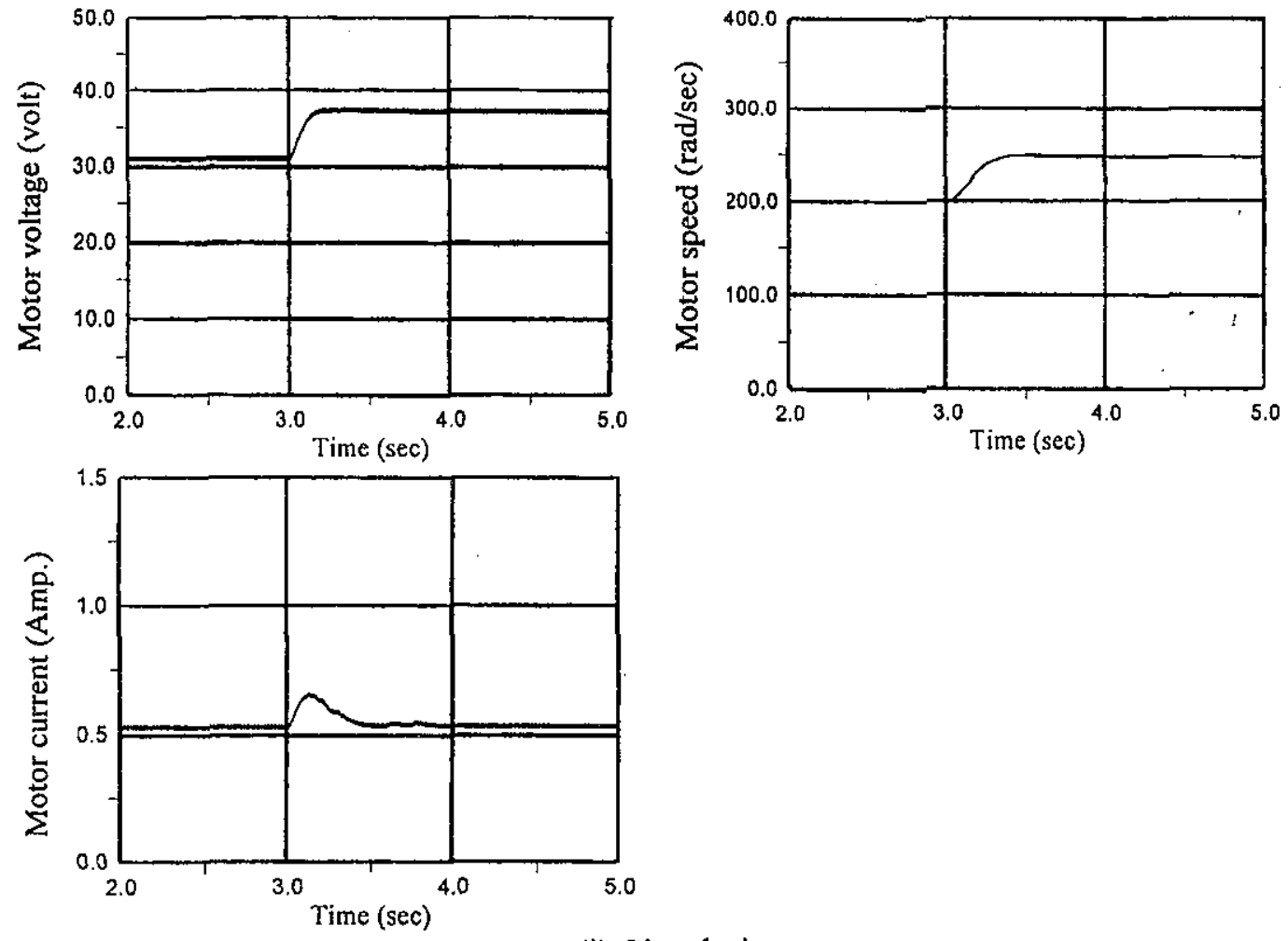

(i) Simulation

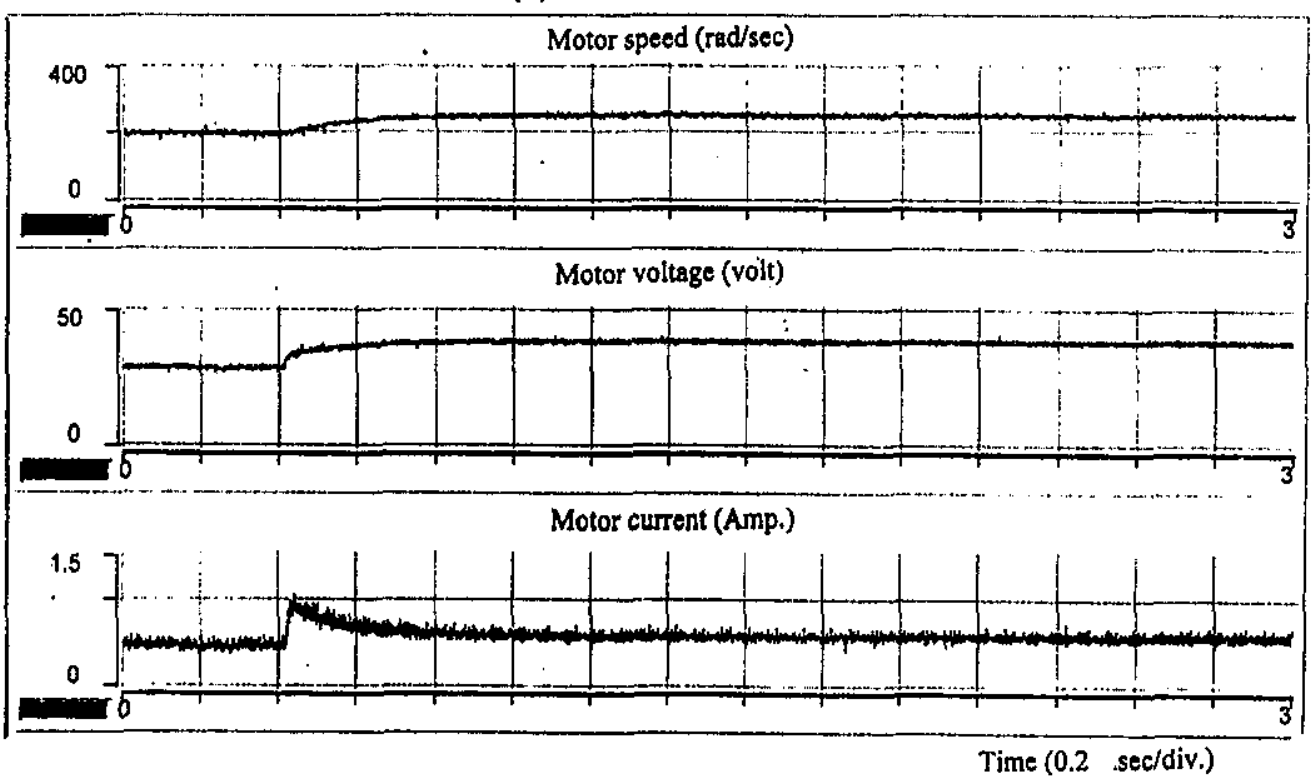

(ii) Experimental

(a) Step up in speed reference 

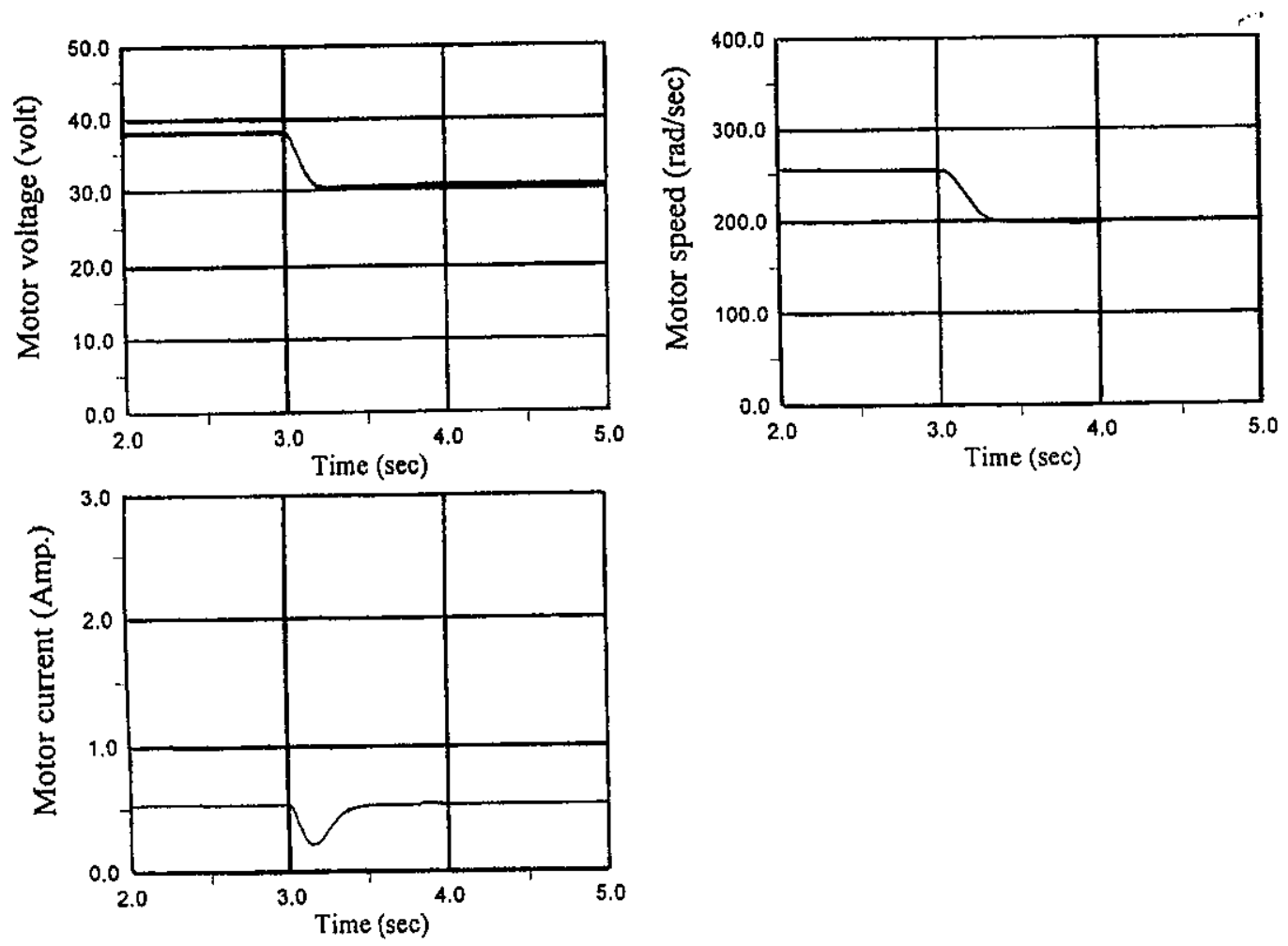

(i) Simulation

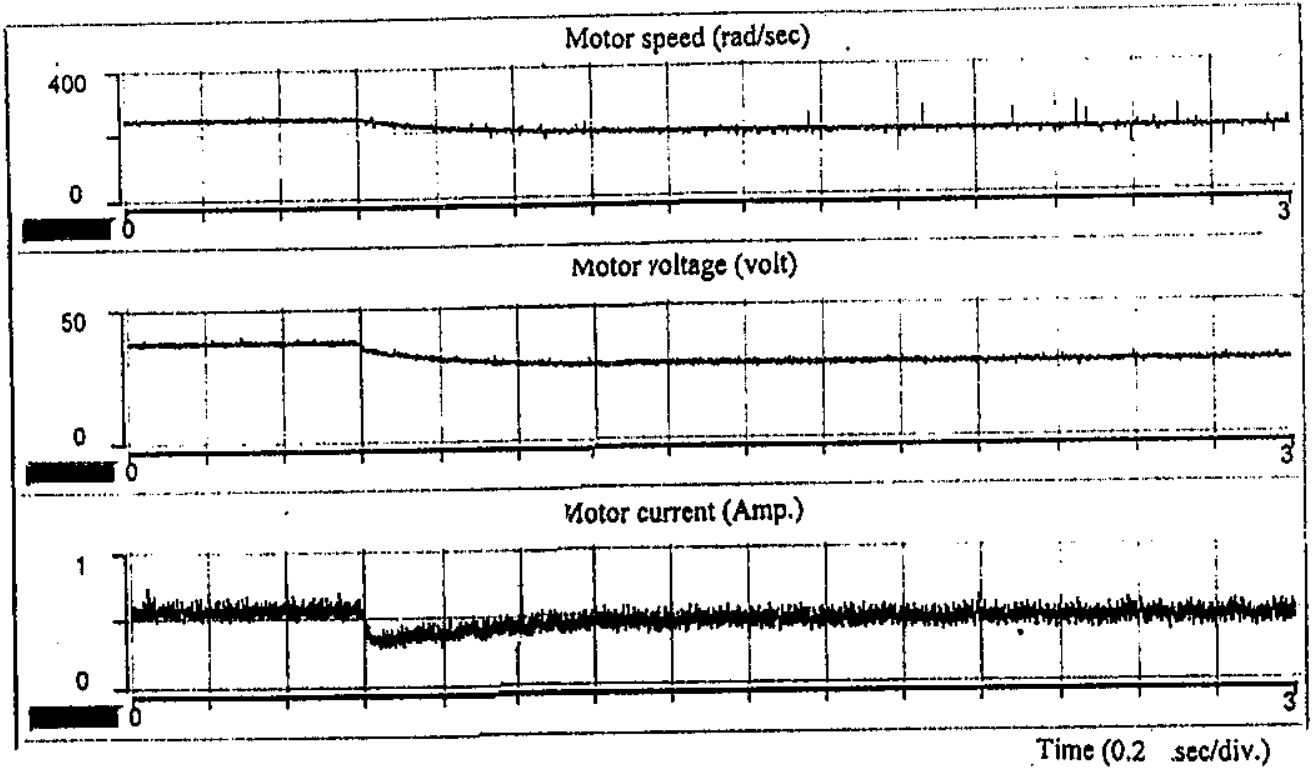

(ii) Experimental

(b) Step down in speed reference

Fig. (9) Responses due to a step change in $\omega_{\text {ref }}$ from 200 to 250 and from 250 to $200 \mathrm{rad} / \mathrm{sec}$ with half full load 


\section{CONCLUSION:}

The paper presents modeling, simulation, and experimental behavior for dynamic and steady state performance of a separately-exited DC motor fed from a single-phase $\mathrm{AC}$ to $\mathrm{DC}$ symmetrical angle controlled converter. This system is used to improvement the supply input power factor. The paper presents a rulebased intelligent error driven-error scaled speed controller to ensure speed reference trajectory tracking. The proposed system is fully controlled using the DSP board. The controller is of a robust design ensuring high dynamic adaptation and self-adjusting error driven control action under both parameter and load excursions. The experimental results ensured the controller robustness, simple and powerful control application capabilities.

\section{APPENDICES:}

- APPENDIX (1):

The parameters of the designed system are as follows:

$\mathrm{V}_{\mathrm{s}(\max )}=71$ volt

$\mathrm{r}_{\mathrm{f}}=2 \mathrm{ohm}$

$\mathrm{C}_{\mathrm{f}}=1200 \mu \mathrm{f}$

$\mathrm{L}_{\mathrm{f}}=0.222$ Henry

$\mathrm{A}=5$ volt

$\mathrm{F}_{\mathrm{s}}=50 \mathrm{~Hz}$.

\section{- APPENDIX (2):}

The test motor is a separately excited DC motor, 55 voit, 50 watt, 1 Ampere, 3000 r.p.m. having the following measured parameters:

$\begin{array}{ll}r_{m}=10.5 \mathrm{ohm} & \mathrm{R}_{\mathrm{f}}=550 \mathrm{ohm} \\ \mathrm{B}=0.0001 \mathrm{~N} \cdot \mathrm{m} . /(\mathrm{rad} / \mathrm{sec}) & \mathrm{L}_{\mathrm{m}}=0.06 \text { Henery } \\ \mathrm{k}_{\mathrm{m}}=0.127 \mathrm{volt} /(\mathrm{rad} / \mathrm{sec}) & \mathrm{J}=0.00015 \mathrm{~kg} \cdot \mathrm{m}^{2}\end{array}$

- APPENDIX (3):

The controller parameters are as follows:
$\gamma_{1}=0.015$
$\gamma_{2}=35$
$\gamma_{3}=0.015$
$\beta \beta=98$
$\mathrm{k}_{0}=0.0035$

\section{REFERENCES:}

[1] S. Weersooiya, A. M. El-Sharkaw, "Adaptive Traction Control For High Performance DC Drives" IEEE Trans. on Energy Conversion, Vol. 4, No. 3, pp. 502-508, September 1989.

[2] A. Brickwedde, " Microprocessor Based Adaptive Speed And Position Control For Electric Drives" IEEE Trans. on Industry Applications, pp. 11541161, September/October 1985. 
[3] Y. Y. Hsu, and W. C. Chan, "Optimal Variable Structure Controller For DC Motor Speed Control” IEE Proc., Vol. 131, No. 6, pp. 233-237, November 1984.

[4] J. Zhang, and T. H. Barton, " Robustness Enhancement Of DC Drives With A Smooth Optimal Sliding Mode Control" IEEE Trans. on Industry Applications, Vol. 27, No. 4, pp. 686-693, July/August 1991.

[5] B. A. White, R. T. Lipezynski, and A. R. Daniels, "A Simple Digital Control Scheme For DC Motor" IEE Proc. B, Vol. 130, pp. 143-147, March 1992.

[6] M. A. El-Shorkawi, and S. Weerasooriya, " Development And Implementation Of Self-Tuning Tracking Controller For DC Motors" IEEE Trans. on Energy Conversions, Vol. 5, pp. 122-128, March 1990.

[7] A. J. Dymock," Analysis Of A Type Of Model Reference Adaptive Control System" IEE Proc., Vol. 112, pp. 743-753, March 1965.

[8] E, H, Mandani," Application Of Fuzzy Logic To Approximate Resoning Using Linguistic Synthesis" IEEE Trans. on Computer, Vol. C-26, No. 12, pp. 1182-1191, December 1977.

[9] S. Weerasooriya, and M. A. El-Sharkawi, "Identification And Control Of A DC Motor Using Back-Propagation Neural Networks" IEEE Trans. on Energy Conversions, Vol. 6, No. 4, pp. 1538-1541, December 1991.

[10] H. F. Soliman, A. M. Sharaf, S. A. Kandil, and M. M. Mansour,“ Intelligent Rule-Based Error Driven Gain Scheduling Controller For Chopper Fed DC Series Motor" Al-Azhar Engineering Fourth International Conference, 16-19 December 1995.

[11] A. S. Abdel-Ghaffar, S. S. Shokralla, and A. M. Sharaf, "An Intelligent Self Adaptive Rule Based Regulator For Permanent Magnet DC Motor Drive" Proceedings of the Cairo IASTED International Conference Computer Application in Industry. Ain-shams University, 26-29 December 1994.

[12] S. S. Shokralla, and M. E. El-Shibiny, “ Dynamic And Steady-State Performance Of A Symmetrical Angle Controlled DC Motor" Engineering Research Bulletin: ISSN 1110-1180, Vol. 23, No. 2, pp. 211-230, 2000.

[13] DSP_CIT Hardware, "DSPACE Digital Signal Processing and Control Engineering GMBH" Germany 1993.

[14] P. Sen, "Thyristor DC drive" Jhon Wiley and Sons Inc., NewYork, Book, 1981. 

توائم ذاتى قائم على قواعد لحاكم سرعه لمحرك تيار مستمر يتم التحكم فيه

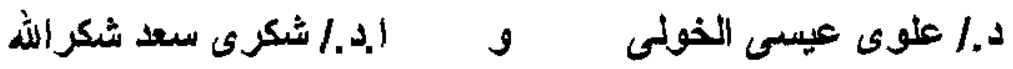 \\ قسم الهندسة الكهربية \\ كلية الهندسة بشبين الكومة الكومية \\ جامعة المنوفية المبنة
}

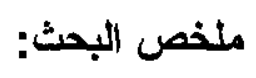

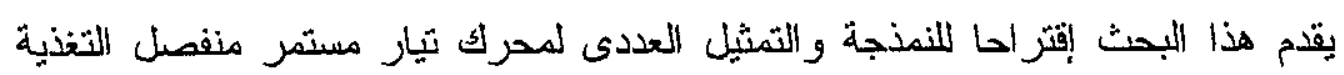

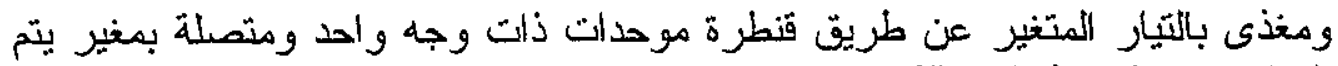

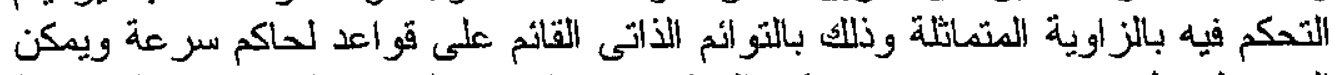

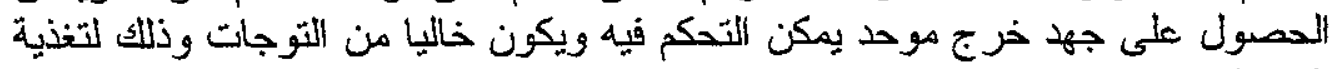
المحرك بغرض التحكم في سر عته

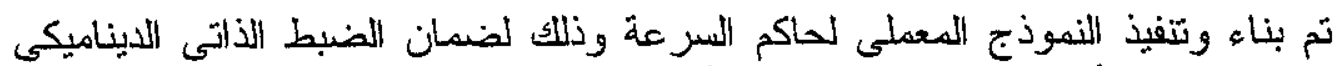

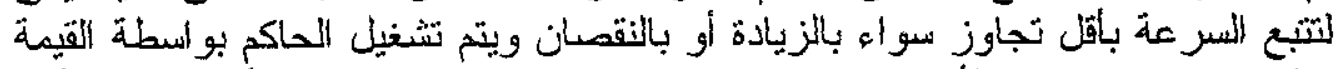

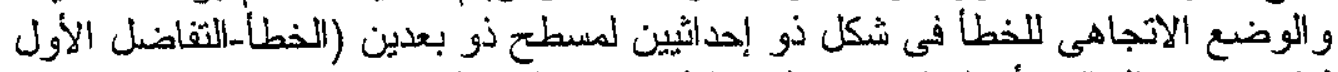

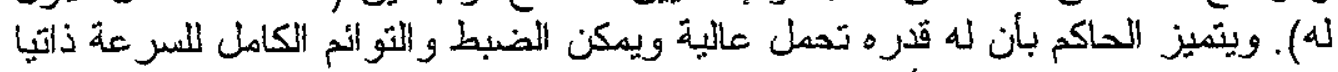

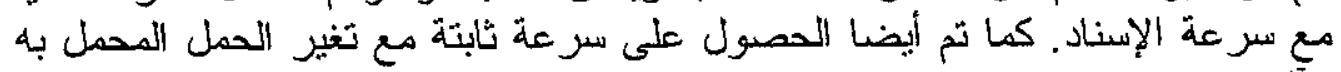
إلآله

يتضمن هذا البحث مقارنة بين النتائج المعملية و النظرية" وقد وجد نطابقا كبير ابينهما.

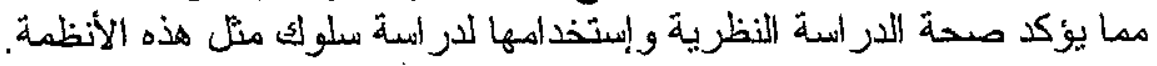

